\title{
FABRIKASI LAPISAN TIPIS C-Cr PADA PERMUKAAN Si DENGAN MENGGUNAKAN METODE SPUTTERING
}

\section{FABRICATION OF TIN LAYER C-Cr ON Si SURFACE USING SPUTERING METHOD}

\author{
P.Purwanto ${ }^{a}$ Yunasfi $^{b}$ dan Salim Mustofa $^{c}$ \\ a,b,c Pusat Sains Teknologi Bahan Maju (PSTBM) - Batan, Kawasan Puspiptek \\ Serpong., Tangerang \\ Email :a ppurwanto88@gmail.com, ${ }^{b}$ yunasfi@gmail.com, ${ }^{c}$ salim.mustofa@gmail.com
}

\begin{abstract}
Abstrak
Telah dilakukan pembuatan lapisan tipis karbon-krom (C-Cr) pada permukaan Si. Pelapisan C-Cr pada permukaan Si merupakan eletrode dalam bentuk lapisan tipis. Pengukuran struktur kristal lapisan tipis $\mathrm{C}-\mathrm{Cr}$ pada permukaan Si dilakukan dengan difraksi sinar-x, pola difraksi yang nampak yaitu puncak $C$ dan $C r$. Ukuran kristalit dan regangan lapisan tipis C-Cr yaitu 18,40 A dan regangan $17,78 \%$. Pengukuran sifat listrk pada pelapisan karbon-krom (CCr) dan tanpa pelapisan meliputi konduktansi dan kapasitansi. Dari hasil pengukuran menunjukkan konduktansi lapisan tipis $\mathrm{C}-\mathrm{Cr}$ dan kapasitansi menurun dengan kenaikan frekuensi, begitu juga dalam bentuk pellet $\mathrm{C}-\mathrm{Cr}$ dan substrat Si. Hasil analisis permukaan dengan SEM menunjukkan lapisan tipis CCr. Pengujian lapisan tipis ini dilakukan guna mengetahui terbentuknya lapian tipis $\mathrm{C}$-Cr dengan ditemukannnya unsur $\mathrm{C}$ dan $\mathrm{Cr}$ pada permukaan substrat $\mathrm{Si}$. Dari spektrum Raman diperoleh panjang gelombang pada puncak yaitu $538 \mathrm{~cm}^{-}$ 1. Hal ini menunjukkan adanya interaksi antara $\mathrm{C}$ dan $\mathrm{Cr}$, sehingga puncak yang nampak adalah puncak karbon.
\end{abstract}

Kata kunci : Lapisan tipis, Difraksi sinar-x, Konduktasni, Permukaan, Raman.

\begin{abstract}
To had been done to make thin film of $\mathrm{C}-\mathrm{Cr}$ on Si surface. Deposition carbon-chrom ( $\mathrm{C}-\mathrm{Cr}$ ) on Si surface was electrode shape in the thin film. The measurement ctystall structure thin film of $\mathrm{C}$-Cr on Si surface tobe done was with $x$-ray diffraction which was $C$ and $\mathrm{Cr}$. The crystall size and strain of $\mathrm{C}-\mathrm{Cr}$ thin film was $18.40 \mathrm{~A}$ and strain $17.78 \%$. The measurement electrical properties on deposition of $\mathrm{C}-\mathrm{Cr}$ and without deposition as follow conductance and capacitance. The result indicated, that conductance of $\mathrm{C}-\mathrm{Cr}$ thin film and capacitance decreased with increasing of frequence and also pellet shape of C$\mathrm{Cr}$ and $\mathrm{C}$ substract. The result of surface morphology with SEM, indicate to had became of thin film $\mathrm{C}-\mathrm{Cr}$ on the Si surface. The examine thin film tobe done for know what the thin film of $\mathrm{C}-\mathrm{Cr}$ was shaped with find out $\mathrm{C}$ and $\mathrm{Cr}$ on the $\mathrm{Si}$ substrate surface. From Raman spectrum tobe find out wave number on the peak $520.56 \mathrm{~cm}-1$, indication that interaction between $\mathrm{C}$ and $\mathrm{Cr}$, so that peeak which visible was pek of $C$.
\end{abstract}

Key word : Thin film, X-ray diffraction, Conductance, Surface, Raman

Diterima (received) : 4 Oktober 2014, Direvisi (reviewed) : 29 Oktober 2014,

Disetujui (accepted) : 16 November 2014 


\section{PENDAHULUAN}

Metode sputtering merupakan teknologi deposisi yang memanfaatkan tumbukan antara ion-ion berenergi tinggi dengan permukaan target yang akan dideposisikan. Tumbukan ini menyebabkan atom-atom target terlepas dari ikatannya dan bergerak menuju substrat akibat adanya transfer momentum selama proses tumbukan, hal ini akan terjadi terus menerus hingga terbentuk suatu lapisan tipis 1 '.

Saat ini pengembangan lapisan tipis sebagai sensor terus dikembangkan, salah satunya adalah lapisan tipis $\mathrm{C}-\mathrm{Cr}$, yang diharapkan lapisan tipis ini dapat bekerja pada suhu kamar. Pemanfaatan lapisan tipis $\mathrm{C}-\mathrm{Cr}$ ini nantinya akan digunakan sebagai sensor ${ }^{2,3) \text {. }}$

Untuk mengetahui komposisi unsur pada lapisan tipis yang dihasilkan dilakukan dengan EDS dan SEM untuk mengetahui bentuk butir dan ketebalan lapisan tipis $\mathrm{C}-\mathrm{Cr}$ yang dihasilkan.

Permasalahannya adalah bagaimana sifat listrik yang akan dihasilkan oleh lapisan tipis C-Cr dari hasil Sputtering $D C$, apakah lapisan ini dapat digunakan secara optimal dalam fungsinya sebagai elemen sensor biomedik 4,5). Tujuan dalam penelitian ini adalah untuk mendapatkan suatu lapisan tipis $\mathrm{C}-\mathrm{Cr}$ yang dapat digunakan untuk sensor.Dalam penelitian ini digunakan substratnya $\mathrm{Si}$ dan lapisan tipisnya $\mathrm{C}-\mathrm{Cr}$. Sensor ini prinsip dasar pengukuran berdasarkan konduktivitas dan kapasitansi lapisan tipis ${ }^{6-9}$.

\section{BAHAN DAN METODE}

\section{Bahan}

Sistem Sputtering yang digunakan dalam proses deposisi lapisan tipis yaitu : Sputtering DC,. Sistem Sputtering terdiri atas sepasang elektroda plat sejajar, anoda dan katoda. Skema DC Sputtering ditunjukkan pada Gambar 1.

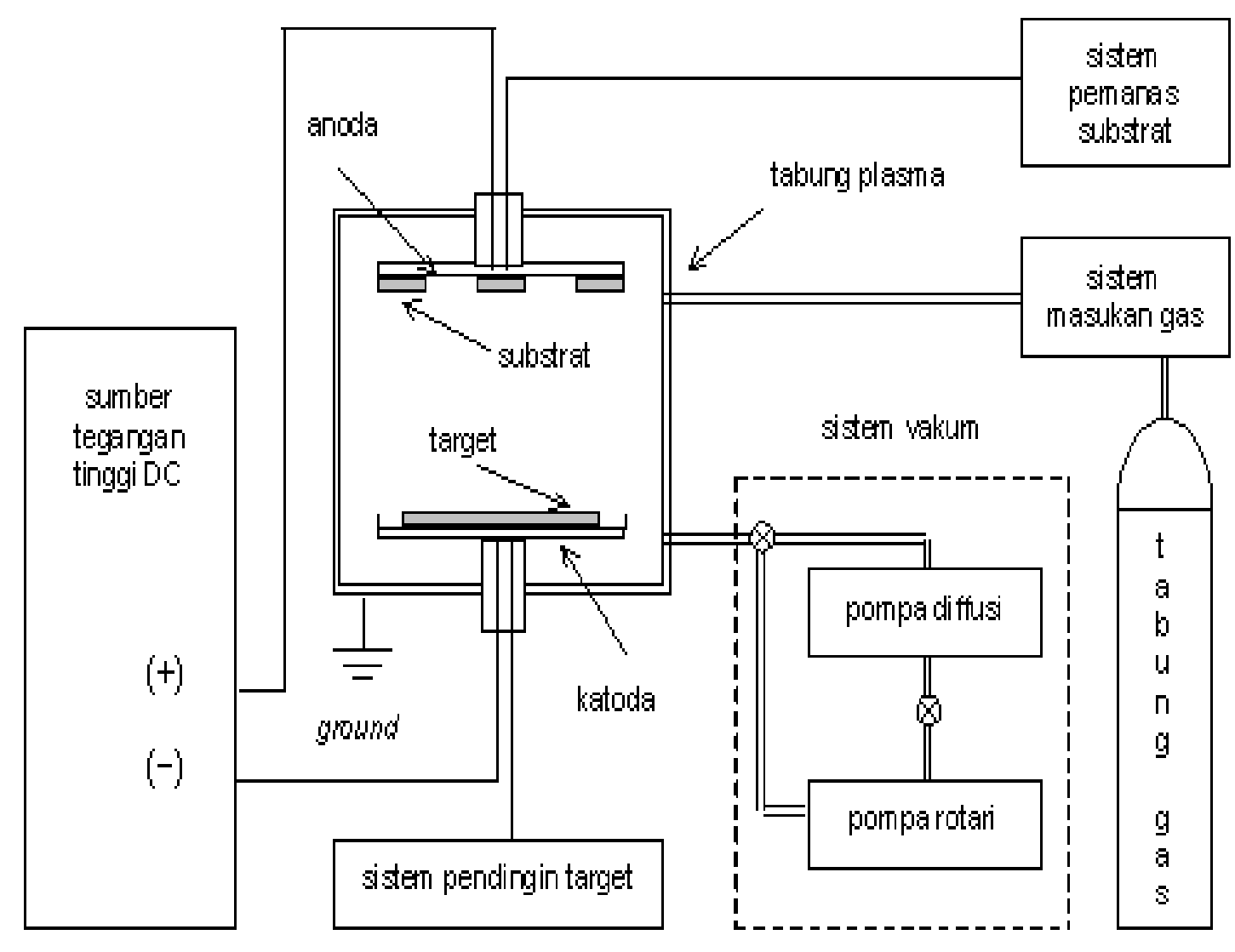

Gambar 1.

Skema Sistem DC Sputtering 

Mustofa)

Target adalah material yang akan didepositkan. Target diletakkan pada katoda, sedangkan substrat dipasang pada anoda yang letaknya berhadapan dengan katoda (target). ${ }^{1)}$. Gas yang digunakan sebagai media pembentuk plasma yaitu gas argon memiliki massa lebih besar daripada gas-gas mulia lainnya dan mudah mengalami ionisasi.

Atom-atom yang terpercik dari permukaan target dalam Sputtering akan bertumbukan dengan molekul-molekul gas. Selama proses ini tekanan gas sangat tinggi dan jalan bebas rata-rata partikel yang terpercik lebih kecil dari jarak antar elektroda, sehingga atom-atom target dapat terdeposit dan berdifusi ke substrat.

Dari Gambar 2, menunjukkkan puncak karbon dan krom. Dari dua puncak ini dilakukan analisis untuk sudut 2 theta dan lebar setengah puncak (FWHM) dengan menggunakan program/gor. Dengan menggunakan persamaan Williamson dan Hall ${ }^{10,11)}$ yaitu :

$$
(\beta \cdot \cos \theta) / \lambda=0,9 / D+(2 \cdot \eta \cdot \sin \theta) / \lambda
$$

dimana : $\beta$ adalah lebar setengah puncak difraksi (FWHM) dalam (rad), $\theta$ sudut Bragg $\left({ }^{\circ}\right), \lambda$ panjang gelombang sinar- $x\left({ }^{\circ} \mathrm{A}\right), \mathrm{D}$ adalah ukuran kristalit $\left({ }^{\circ} \mathrm{A}\right)$ dan $\eta$ regangan kristal.

Dari data sudut 2 theta dan lebar setengah puncak dibuat kurva antara .cos $\theta / \lambda$ terhadap $\sin \theta / \lambda$, diperoleh ukuran kristal dan regangan kristal $\mathrm{C}-\mathrm{Cr}$.

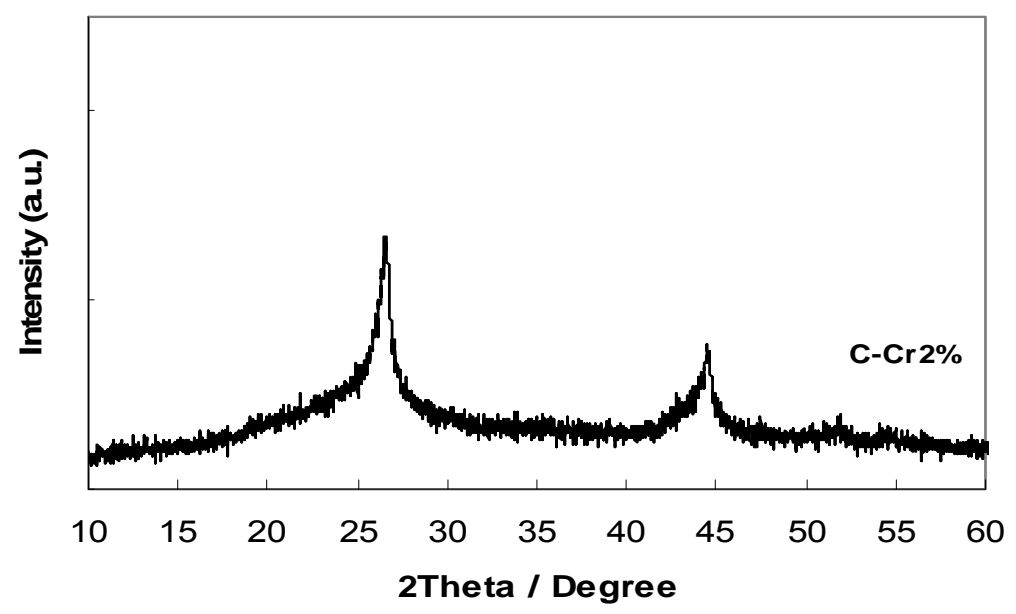

Gambar 2.

Pola Difraksi Sinar-x Lapisan Tipis C-2\% Cr

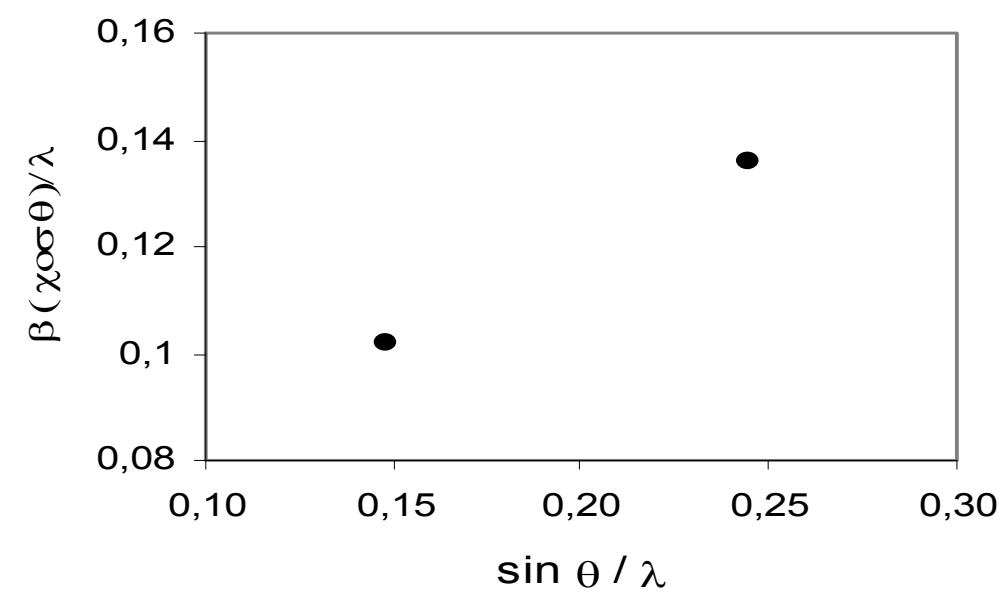

Gambar 3.

Hubungan Antara $\beta . \cos \theta / \lambda$ terhadap $\sin \theta / \lambda$ Untuk Menentukan Ukuran Kristalit dan Regangan $\mathrm{C}-2 \% \mathrm{Cr}$ 
Dengan mempergunakan persamaan 1, diperoleh ukuran kristalit dan regangan lapisan tipis $\mathrm{C}-2 \% \mathrm{Cr}$, ditunjukkan pada Tabel 1.

Tabel 1.

Parameter Lapisan Tipis C- $2 \% \mathrm{Cr}$

\begin{tabular}{ccc}
\hline Sampel & Ukuran, $\mathrm{D}(\AA)$ & Regangan \\
\hline $\mathrm{C}-2 \% \mathrm{Cr}$ & 18,40 & 17,78 \\
\hline
\end{tabular}

Dari hasil pengamatan dengan difraksi sinar-x, yaitu ukuran kristal dan regangan, peneliti belum mendapatkan kondisi pesyaratan untuk digunakan sebagai sensor. Biasanya yang dipakai pada sensor yaitu sifat listrik terutama konduktansi kapasitansi. Konduktivitas Listrik

Gambar 4, menunjukkan kurva konduktivitas dan kapasitansi lapisan tipis C$\mathrm{Cr}$ pada permukaan Si. Dari gambar spektrum terlihat konduktivitas relatif stabil terhadap frekuensi. Kapasitansi $\mathrm{C}-\mathrm{Cr}$ turun seiring dengan naik frekuensi sampai 1000 $\mathrm{Hz}$, sedangkan diatas frekunsi $1000 \mathrm{~Hz}$ turun tidak begitu tajam terhadap frekuensi.

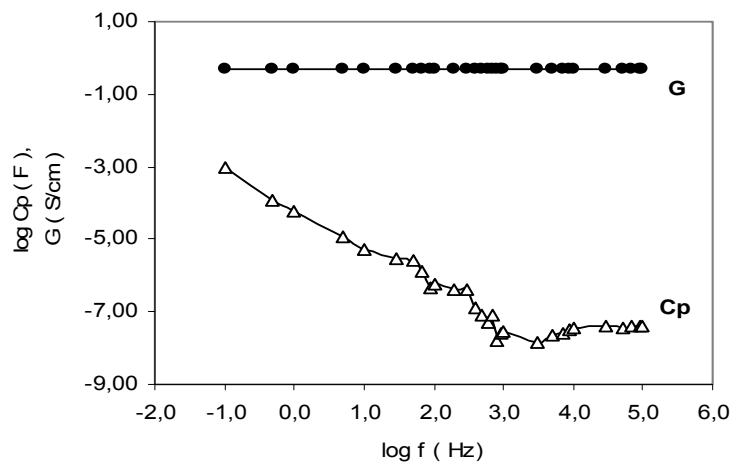

Gambar 4a.

Hubungan Antar Konduktivitas dan Kapasitansi Terhadap Frekuensi pada C-2\% Cr dalam Bentuk Pelet

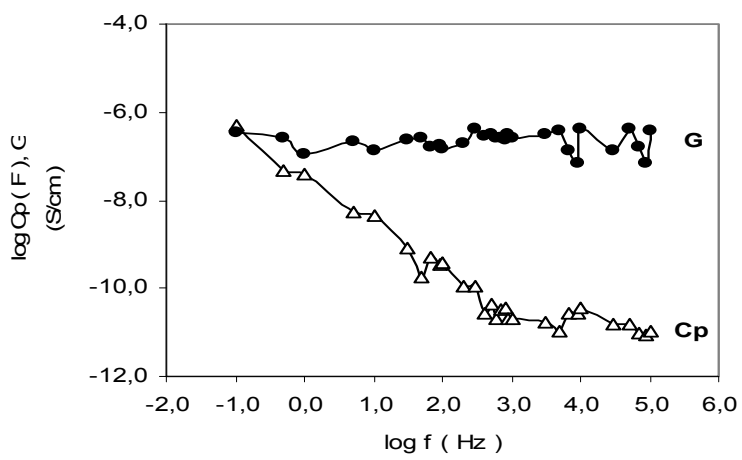

Gambar 4b.

Hubungan Antar Konduktivitas dan Kapasitansi Lapisan Tipis C-2\% Cr

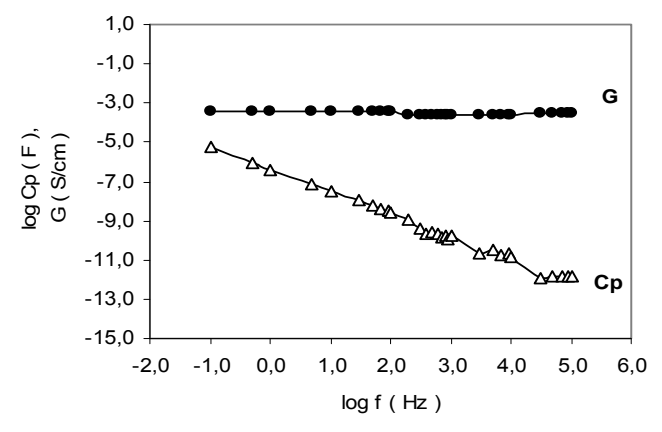

Gambar 4c.

Hubungan Antar Konduktivitas dan Kapasitansi Pada Permukaan Si

Dari Gambar 4, dapat dihitung konduktivitas dan kapasitansi $\mathrm{C}-2 \% \mathrm{Cr}$ dalam bentuk pellet, lapisan tipis $\mathrm{C}-2 \% \mathrm{Cr}$ dan substrat Si, yang ditunjukkan pada Tabel 2 .

Tabel 2.

Parameter Listrik Bahan C-2\%Cr

\begin{tabular}{lcc}
\hline Sampel & $\begin{array}{c}\text { Konduktivitas } \\
(\mathrm{S} / \mathrm{cm})\end{array}$ & $\begin{array}{c}\text { Kapasitansi } \\
(\mathrm{F})\end{array}$ \\
\hline Pellet & $49,397 \times 10^{-2}$ & $2,504 \times 10^{-5}$ \\
Thin Film & $3,366 \times 10^{-4}$ & $3,991 \times 10^{-7}$ \\
Substrat & $2,251 \times 10^{-7}$ & $1,213 \times 10^{-8}$ \\
\hline
\end{tabular}

Pada Tabel 2, konduktivitas tinggi didapat pada bahan $\mathrm{C}-2 \% \mathrm{Cr}$ dalam bentuk pellet, terendah pada substratnya yaitu Si. Sedangkan nilai konduktivitas lapisan tipis (thin film) $\mathrm{C}-2 \% \mathrm{Cr}$ adalah berada antara konduktivitas pellet dan substrat. Dari pengamatan yang bersifat menghantarkan listrik yaitu $\mathrm{Cr}$, sedangkan $\mathrm{C}$ bersifat isolator. Dalam penelitian lebih lanjut yaitu $\mathrm{Cr}$ diharapkan masuk kedalam $\mathrm{C}$ atau diluar $\mathrm{C}$, hal ini dapat teramati dengan alat TEM (Tunneling Emision Microscopy).

Kapasitansi bahan $\mathrm{C}-2 \% \mathrm{Cr}$ tinggi didapat pada bahan yang berbentuk pellet, terendah pada substratnya, sedangkan lapisan tipis berada antara kapasitansi bentuk pellet dan substrat. Dari hasil yang diperoleh berupa nilai konduktansi dan kapasitansi untuk penggunaan sebagai sensor belum didapatkan kondisi yang optimal.

\section{Morfologi Permukaan}

Pada Gambar 5, menunjukkan morfologi permukaan Si-C-2\%Cr serta lapisan tipis C$2 \% \mathrm{Cr}$ dengan pembesaran sama yaitu 1500X. Dari Gambar 5a, menunjukkan permukaan bahan $\mathrm{C}-\mathrm{Cr}$ hasil pelet, Gambar 
$5 \mathrm{~b}$ menunjukkan penampang permukaan bujur, nampak morfologi Si sebagai substrat dan $\mathrm{C}-\mathrm{Cr}$ sebagai lapisan tipis nampak. Gambar 5c menunjukkan lapisan tipis $\mathrm{C}-\mathrm{Cr}$ pada permukaan $\mathrm{Si}$.

Pengujian lapisan tipis ini dilakukan guna mengetahui apakah telah terbentuknya lapian tipis $\mathrm{C}-\mathrm{Cr}$ dengan ditemukannnya unsur $\mathrm{C}$ dan $\mathrm{Cr}$ dalam lapisan. Dengan menggunakan EDS maka didapatkan unsur pembentuk lapisan tipis.

Nilai resistansi suatu lapisan tipis $\mathrm{C}-\mathrm{Cr}$ atau semakin meningkatnya nilai konduktivitas, maka dikatakan semakin baik hasil deposisi tersebut. Hal ini berdasarkan pada pertimbangan substrat tempat penumbuhan lapisan tipis tersebut. Substrat yang digunakan adalah silikon yang mana diketahui bahwa substrat silikon adalah bahan isolator. Jadi apabila diatasnya ditumbuhkan suatu lapisan tipis, maka penilaian yang ditentukan adalah munculnya suatu nilai resistansi atau konduktivitas pada permukaan silikon tersebut. Dengan munculnya nilai resistansi ini maka dapat dikatakan bahwa telah terbentuk suatu lapisan tipis pada permukaan silikon tersebut.

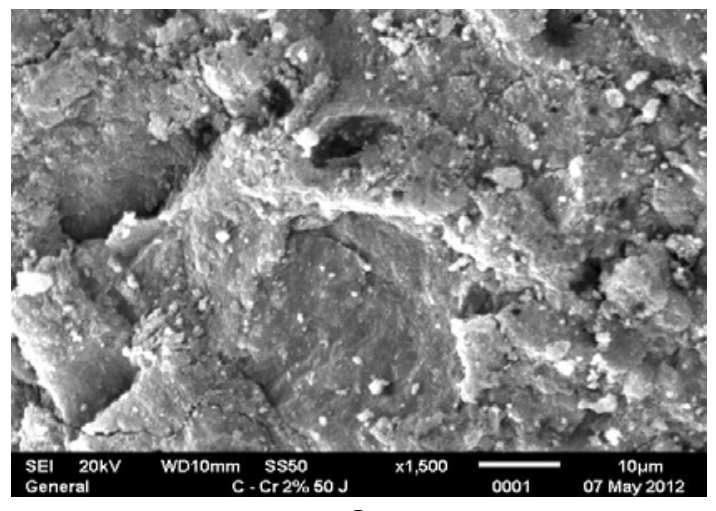

a

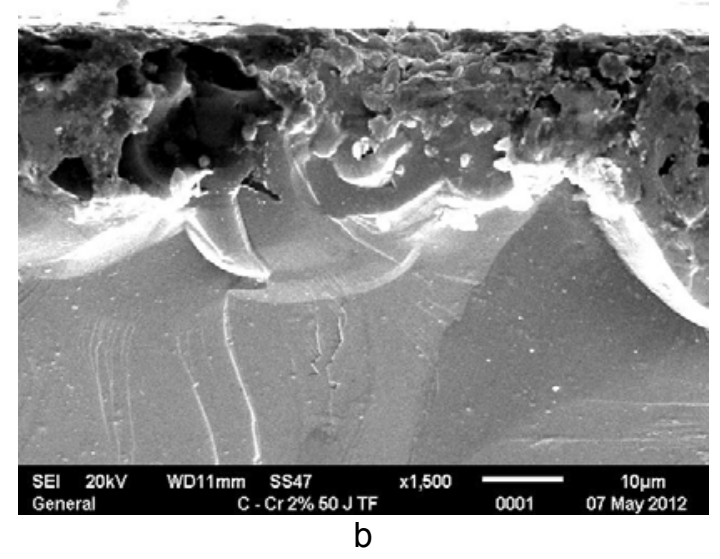

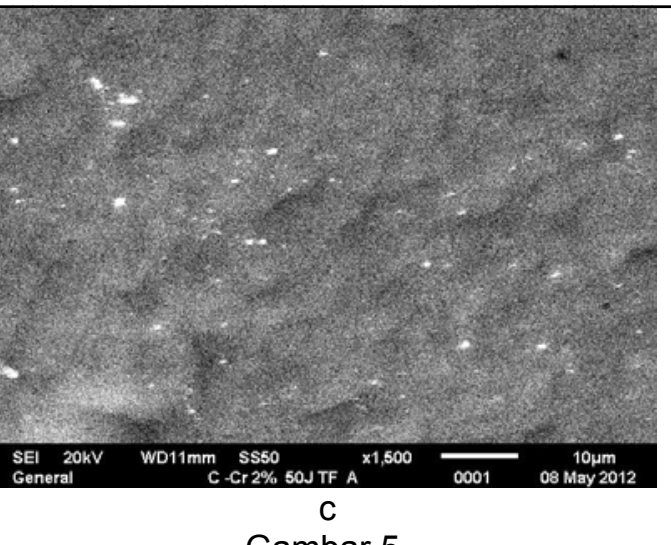

Gambar 5.

Morfologi Permukaan Pada Bahan C-Cr

a). Permukaan Lintang $\mathrm{C}-\mathrm{Cr}$

b). Permukaan Bujur C-Cr

c). Permukaan Lintang Lapisan Tipis

Semakin kecil nilai resistansi yang didapatkan berarti bahwa lapisan tipis tersebut semakin bersifat konduktor yang mana sifat inilah yang menjadi kepastian dalam pembuatan suatu elemen sensor pada permukaan substrat.

Dari hasil pembahasan tentang morfologi permukaan tipis C-Cr, menurut S.G Zotawa dkk 12) sifat lapisan tipis dan stabilitas permukaan tergantung pada struktur dan komposisi fasa lapisan.

\section{Raman Spektroskopi}

Pada Gambar 6, menunjukkan spketrum Raman lapisan tipis $\mathrm{C}-\mathrm{Cr}$ pada permukaan Si.

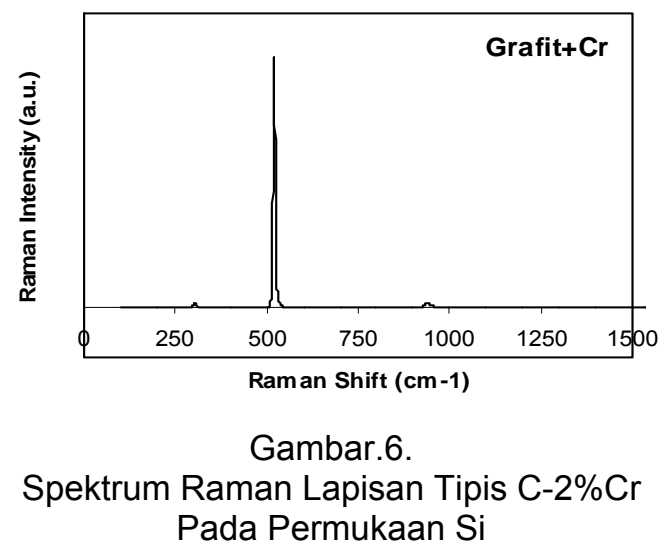

Dari spektrum Raman diperoleh bilangan gelombang yaitu $520,56 \mathrm{~cm}^{-1}$. Hal ini menunjukkan adanya interaksi antara $\mathrm{C}$ dan $\mathrm{Cr}$, sehingga puncak yang nampak adalah puncak karbon. Bila tidak terjadi interaksi antara C-Cr, maka pada spektrum Raman akan nampak masing-masing puncak. 


\section{SIMPULAN}

Dari hasil penelitian ini dapat disimpulkan bahwa struktur kristal yang nampak pada lapisan tipis $\mathrm{C}-\mathrm{Cr}$ pada permukaan Si sudah terbentuk. Ukuran kristal dan regangan lapisan tipis $\mathrm{C}-\mathrm{Cr}$ yaitu $18,40{ }^{\circ} \mathrm{A}$ dan regangan $17,78 \%$. Sifat listrik pada pelapisan karbonpkrom ( $\mathrm{C}-\mathrm{Cr}$ ) dan tanpa pelapisan menunjukkan konduktansi lapisan tipis $\mathrm{C}-\mathrm{Cr}$ dan kapasitansi menurun seiring dengan nainya frekuensi, begitu juga dalam bentuk pellet $\mathrm{C}-\mathrm{Cr}$ dan substrat Si. Morfologi permukaan $\mathrm{C}-\mathrm{Cr}$ dengan SEM menunjukkan terbentuk lapisan tipis C-Cr pada permukaan Si. Dari spektrum Raman diperoleh bilangan gelombang yaitu 520,56 cm-1, hal ini menunjukkan adanya interkasi antara $\mathrm{C}$ dan $\mathrm{Cr}$, sehingga puncak yang nampak adalah puncak karbon.

\section{UCAPAN TERIMA KASIH}

Penelitian ini merupakansalah satu bagian dari kegiatan Program Insentif PKPP tahun 2012. Untuk itu penulis menyampaikan ucapan terima kasih kepada Kemenristek sebagai pendukung dana dan manajemen atas dukungan fasilitas dalam kegiatan ini.

\section{DAFTAR PUSTAKA}

1. B.A. Tjipto Sujitno, Aplikasi Plasma dan Teknologi Sputtering Untuk Surface Treatment, Diktat Kuliah. P3TM BATAN Yogyakarta, 5-9 Mei 2003.

2. N. Sinha, Carbon Naotubes for Biomedical Application, Tansaction on Nanobioscience,No.2,2005, p180.

3. N. Sinha, J. Ma, and J.T.W. Yeow, Carbon Nanotube-Based Sensors, J.of. Nanosience and Nanotechnology, Vol.6, 2006, p573.
4. H. Sudjatmoko dan B.A. Tjipto Sujitno," Workshop Sputtering Untuk rekayasa Permukaan Bahan", Diktat Kuliah. P3TM BATAN Yogyakarta, 5-9 Mei 2003.

5. Patricia Lubis, Altje Ltununuwe dan Toto Winata, Penumbuhan Nanopartikel Nikel Dengan DC Unbalanced Magnetron Sputtering, J. Nanosains dan Nanoteknologi, Edisi Khusus Agustus 2009, p71-73.

6. S. Hwang, H. Choi, Y. Kim, Y. Han, H. Kim, M. Kang and M. Jeon, Influence of the Electrical Conductivity of the Silicon Substrate on the Growth of MWCNT, J of the Korean Physical Society, Vol.58,No.2, 2011, p248.

7. P.R. Bandaru, Electrical Properties and Application of Carbon Nanotube Structure, J.of. Nanoscience and Nanotechnoloy, Vol. 7, 2007, p1.

8. C. Lu and Y. Wing Mai, Anomalous Electrical Conductivity and Percolation in Carbon Nanotubes Composite, J. Materials Science, Vol.43, 2008,p6011.

9. A.M. Bondar and I. lordache, Carbon/ceramic Composite Designed for electrical Application, J.of Optoelectronics and and Advance Materials, Vol.8, 2006, p631.

10. K.G. Williamson and W.H. Hall, "X-Ray Line Broading From Filed $\mathrm{Al}$ and Wolfram”,Acta.Met, Vol. 1 ,No.1 1953, p22.

11. K.N.R. Rehani, P.B. Joshi, K.N. Lad and A. Pratap, Crystallite Size Estimatin of Elemental and Composite Silver Nano Powder Using XRD Prisiciple, Indian J.of Pure Physics, Vol. 44, 2006, p157.

12. S.G. Zotawa, R.G. Vitchev and B. Blanpain," Phase Composition of $\mathrm{Cr}-\mathrm{C}$ Thin Film Deposite by a Double Magnet Sputtering System, Surface and Interface System.30 (2000) 544-548. 